\title{
BILATERAL VARIATION IN THE ORIGIN OF INFERIOR PHRENIC ARTERY AND ITS CLINICAL IMPLICATIONS: A CASE REPORT
}

\author{
Gopal Gupta1, Kamal Singh², Sudha Chhabra³, Aarti Rohilla4, Veena Gupta ${ }^{5}$
}

\section{HOW TO CITE THIS ARTICLE:}

Gopal Gupta, Kamal Singh, Sudha Chhabra, Aarti Rohilla, Veena Gupta. "Bilateral Variation in the Origin of Inferior Phrenic Artery and its Clinical Implications: A Case Report". Journal of Evolution of Medical and Dental Sciences 2014; Vol. 3, Issue 36, August 18; Page: 9465-9469, DOI: 10.14260/jemds/2014/3221

INTRODUCTION: IPA usually originates from aorta as a first lateral branch just above the celiac trunk to supply mainly to the suprarenal gland and the diaphragm. Besides this left IPA may give rise to a small number of branches that serve to supply the superior pole of the spleen and the proximal portion of the stomach. ${ }^{[1]}$ The right IPA potentially communicates with the intra-hepatic arteries and one of the most common sources of extra blood supply to liver as collateral pathways.[2,3] IPA usually develops from lateral splanchnic branch of dorsal aorta.

The IPA bud out from the highest suprarenal artery and the permanent renal artery sprouts from the lowest suprarenal artery.[4] The roentgenographic anatomy of phrenic arteries has been described in detail by Kahn et al..5] Variation of the IPA and their relations to the surrounding structures are important in regard to intra-abdominal surgeries. Ligation or damage to these arteries without knowing the variations during surgical application may cause partial or total visceral ischemia or failure Though the description of IPA is very little in out text their importance has been increased in recent years due to their involvement in the arterial supply and the growth of hepatocellular carcinoma (HCC).[6,7]

For trans-catheter embolization of unresectable HCC, it is very important to know the exact origin and branching pattern of IPA's especially right IPA[6,7,8, and 9] Vascular variations are constantly observed in dissections of adult cadavers.[10] IPA usually arises from aorta and celiac trunk and less frequently from renal, hepatic or gastric arteries. They also contributed to the arterial supply of the adrenal glands and have importance in angiographic examinations of adrenal lesions. ${ }^{[5,11]}$ The IPA can contribute to hemoptysis, especially with the pulmonary abnormality in the lung base. [9]

CASE REPORT: The present report was based on the bilateral variation seen during observed during the routine dissection of abdominal cavity in an embalmed adult male cadaver in the department of anatomy Pt. B. D. Sharma, PGIMS Rohtak. In the present case IPA on left side arose from the celiac trunk and on the right IPA originated directly from right renal artery.

DISCUSSION: Due to lack of much data regarding the anatomical variation in the branches of IPA there were certain studies done, which provides us potential clinical application and additional data to contemporary anatomical literature. Here, in our study we observed that the right IPA arose from right renal artery and left IPA arose as a separate branch from the celiac trunk. Petrella $S$ et al in their study concluded the presence of the IPA from celiac trunk.

They observed that $34.85 \%$ of the 89 analysed cadavers were having arteries aroused from celiac trunk and out of which $21.35 \%$ of 89 cadavers were having artery of the left side. [12]

Baker RJ in the 4th edition of Master of Surgery described the origin of the IPA was from aorta or from celiac trunk or from the right renal artery. [13] 
The American edition of Gray's anatomy gives the complete text books claims that IPA took origin both from celiac trunk or aorta as well as alternative origin from renal or accessory renal, left gastric, hepatic and Gonadal arteries.[14]

Goka et al concluded the CT based study in which they found most frequent site of origin were from aorta and celiac trunk with 46\% right IPA were from aortic origin and 52\% left IPA were from celiac trunk. [7] They also observed that right IPA arising from the right renal artery in $9 \%$ of cases studied and other alternative origins like left gastric, hepatic, superior mesenteric and spermatic were less than $4 \%$ frequently on either right or the left side.

Loukas et al studied the origin of the left and right IPA as a single rooted artery or separately and determined that it's originated from the celiac trunk or the aorta as a single root ${ }^{[1]}$ Pio et al found the majority of IPA arising from the aorta (61.6\%), with $28.2 \%$ of the IPA originating from the celiac trunk and the reminder originating from either renal, left gastric or middle adrenal artery. [15]

The knowledge of this type of variation is important so that the surgeons must be cautious to avoid unintentional sectioning of small calibre arteries, as it may occur during celiac artery decompression in compression syndrome of the celiac trunk by the median arcuate ligament. According to Loukas et al in 2005 the IPA is the major source of collateral or parasitized arterial supply to HCC, second only to hepatic artery. [1]

The IPA can be one of the systemic arteries that contribute to the trans-pleural systemic pulmonary arterial anastomosis, especially when the pulmonary abnormality involves lung base. $[9,1]$

CONCLUSION: The variation in the bilateral IPA can result in unnoticed hemorrhage as a result of cutting of the vessel or ischemia caused by the ligature of a vessel during surgery, so it is important for the surgeons and radiologists to know about variations related to IPA.

The knowledge of right IPA was always important because it was also associated with HCC and serves as a major collateral artery adjunct to the hepatic artery. These findings could have major implication in the trans-catheter embolization of HCC patients. This case report has provided some additional evidence to the researchers and anatomists to enhance the understanding of both IPA and their significance.

\section{REFERENCES:}

1. Loukas M, Hullett J, Wagner T. Clinical anatomy of the inferior phrenic artery. Clin Anat 2005, 18 (5): 357-365.

2. Takeuchi Y, Arai Y, Inaba Y, Ohno K, Maeda T, Itai Y. Extrahepatic arterial supply to the liver: observation with a unified CT and angiography system during temporary balloon occlusion of the proper hepatic artery. Radiology 1998,209:121-128

3. Yamagami T, Kato T, Tanaka O, Hirota T, Nishimura T. Influence of extrahepatic arterial inflow into the posterior segment or caudate lobe of the liver on repeated hepatic arterial infusion chemotherapy. J Vasc Interv Radiol 2005,16 (4): 457-463

4. Dutta AK. Circulatory System in Essentials of Human Embryology. $6^{\text {th }}$ ed Book International, Kolkata, pp181-182. (2010).

5. Kahn PC. Selective angiography of inferior phrenic arteries. Radiology 1967,88: 1-3.

6. Tanabe N, Iwasaki T, Chida N, et al. Hepatocellular carcinomas supplied by inferior phrenic arteries. Acta Radiol 1998,39: 443-446. 
7. Gokan T, Hashimoto T, Matsui S, Kushihashi T, Nobusawa H, Munechika H. Helical CT demonstration of dilated right Inferior phrenic arteries as extrahepatic collateral arteries of hepatocellular carcinomas. J Comput Assist Tomogr 2001,25:68-73.

8. Chung JW, Park JH, Han JK, Choi BI, Kim TK, Han MC. Transcatheter oily chemoembolization of the inferior Phrenic artery in hepatocellular carcinoma: the safety and potential therapeutic role. J Vasc Interv Radiol 1998,9:495-500.

9. Duprat G, Charnsangavej C, Wallace S, Carrasco CH. Inferior phrenic artery embolization in the treatment of hepatic neoplasms. Acta Radiol 1988, 29:427-429.

10. Lipshutz B. A composite study of the coeliac trunk artery. Am Surg 1917,65: 159-169.

11. Kahn PC, Nickrosz LV. Selective angiography of adrenal glands. Am J Roentgenol Radium Ther Nucl Med 1967,101:739-749.

12. Petrella S, Rodrigues CFS, Sgrott EA, Fernandez GJM, Marques SR, Prates JC. Origin of inferior phrenic arteries in the celiac trunk. Int J Morphol 2006, 24 (2): 275-278

13. Baker RJ, Fischer JE (2001) Mastery of surgery. 4th ed. Lippincott, Williams \& Wilkins, pp 691692.

14. Gray H (1985) Anatomy of the human body. 30th ed. Baltimore: Williams \& Wilkins, pp 746747.

15. Piao DX, Ohtsuka A, Murakami T. Typology of abdominal arteries, with special reference to inferior phrenic arteries and their esophageal branches. Acta Med Okayama 1998,52:189-196.

Fig. 1: Showing branches of Celiac Trunk (CT) as Splenic Artery (SA), Common Hepatic Artery (CHA), Left Gastric Artery (LGA), and Left Inferior Phrenic Artery (LIPA). Others are Superior Mesenteric Artery (SMA) and Diaphragm (DIA).

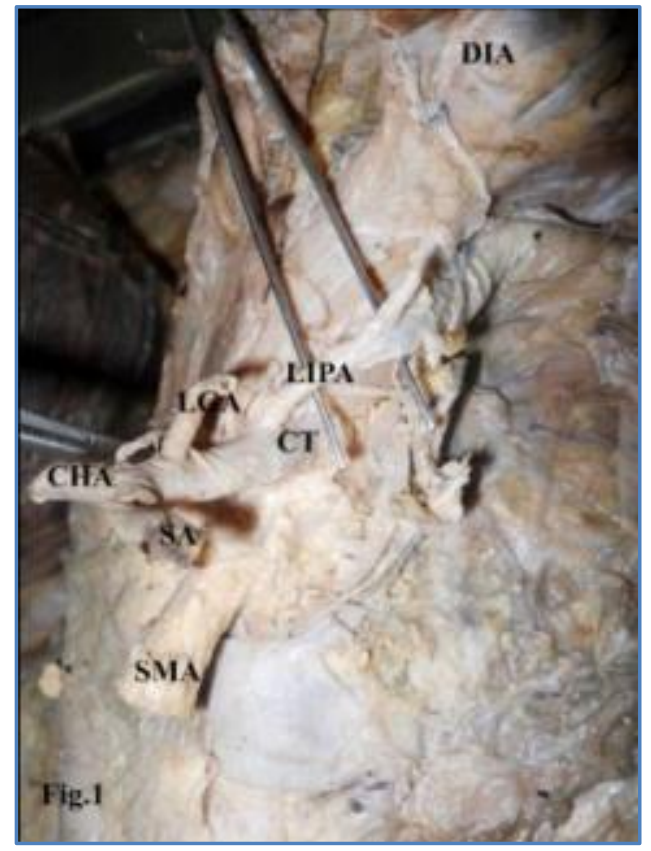

\section{Fig. 1}




\section{CASE REPORT}

Fig. 2: Showing branches of Celiac Trunk (CT) as Splenic Artery (SA), Common Hepatic Artery (CHA), Left Gastric Artery (LGA), and Left Inferior Phrenic Artery (LIPA) on Left Side. On the other side (Right) showing Right Renal Artery (RRA) and Its Branches as Right Inferior Phrenic Artery (RIPA) and Inferior Suprarenal Artery (ISRA).

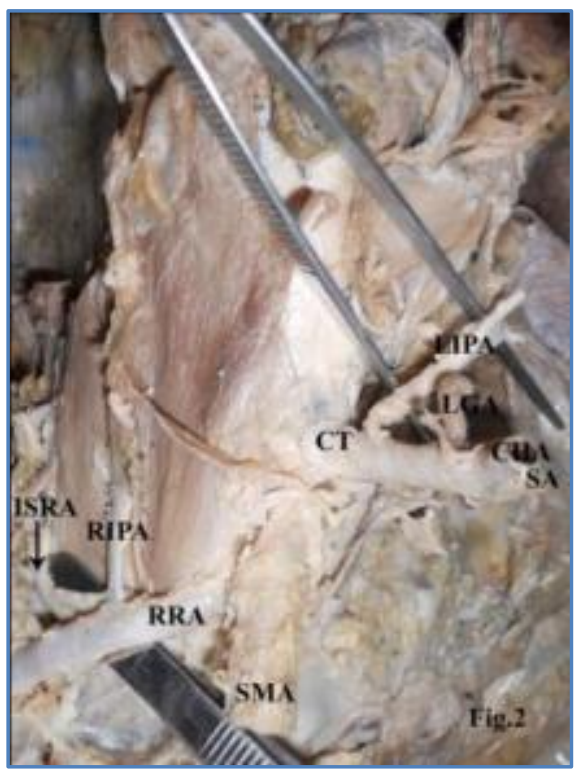

\section{Fig. 2}

Fig. 3: Showing Right Renal Artery (RRA) and Its Branches as Right Inferior Phrenic Artery (RIPA) and Inferior Suprarenal Artery (ISRA). Others are Suprarenal Gland (SRG), Right Kidney (RK), and Diaphragm (DIA).

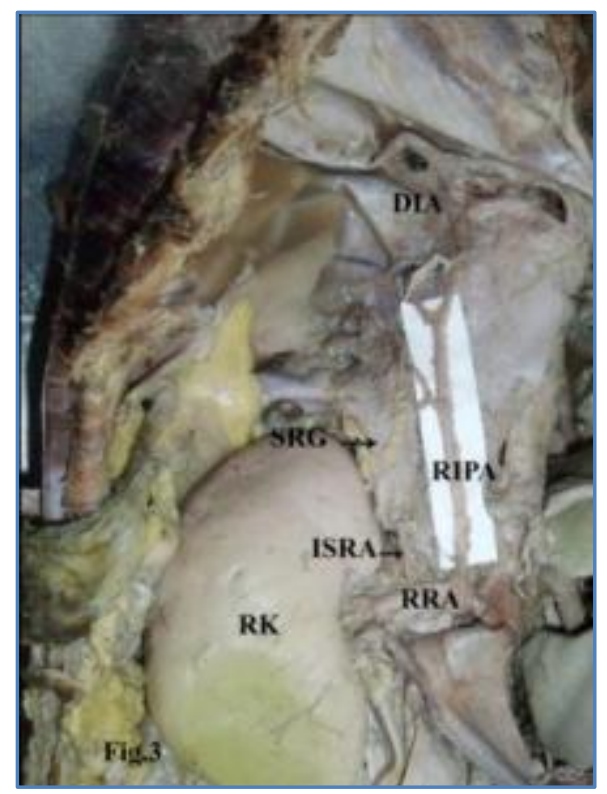

Fig. 3 


\section{CASE REPORT}

\section{AUTHORS:}

1. Gopal Gupta

2. Kamal Singh

3. Sudha Chhabra

4. Aarti Rohilla

5. Veena Gupta

\section{PARTICULARS OF CONTRIBUTORS:}

1. Assistant Professor, Department of Anatomy, Pt. B. D. Sharma, Rohtak.

2. Assistant Professor, Department of Anatomy, Pt. B. D. Sharma, Rohtak.

3. Senior Professor, Department of Anatomy, Pt. B. D. Sharma, Rohtak.

4. Assistant Professor, Department of Anatomy, Pt. B. D. Sharma, Rohtak.

5. Professor, Department of Pathology, Pt. B. D. Sharma, Rahtak.

\section{NAME ADDRESS EMAIL ID OF THE CORRESPONDING AUTHOR:}

Dr. Gopal Gupta,

Assistant Professor,

Department of Anatomy,

Pt. B. D. Sharma, Rohtak,

H. No-9 J/7, Medical Campus,

Rohtak, Haryana.

Email: drgopalanatomy@gmail.com

Date of Submission: 30/07/2014.

Date of Peer Review: 31/07/2014.

Date of Acceptance: 09/08/2014.

Date of Publishing: 18/08/2014. 